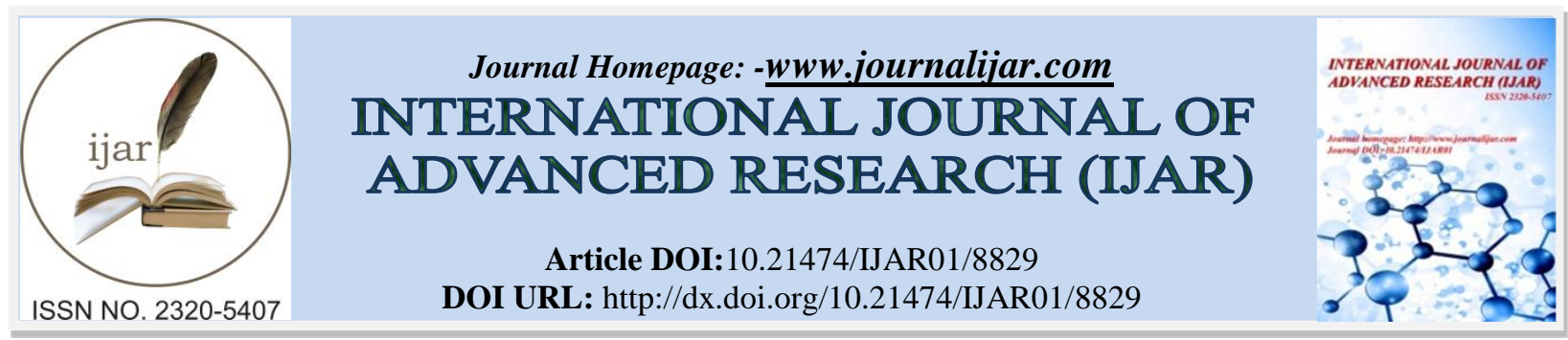

RESEARCH ARTICLE

\title{
STATUS OF EDENTULOUS RIDGE AND ITS ASSOCIATION WITH DIET AMONG ADULT RURAL POPULATION OF MANGALORE TALUK.
}

\author{
Dr. Mallika S Shetty, Dr. Sanath Shetty and Dr. Subin Job.
}

\section{Manuscript Info}

Manuscript History

Received: 06 February 2019

Final Accepted: 08 March 2019

Published: April 2019

Key words:-

edentulism, nutrition, edentulous ridge.

\begin{abstract}
Teeth provide the ability to chew a wide variety of foods of different textures and nutritional values. The aged grouped form with all their teeth extracted is a problem tends to worsen when no healthcare measures are taken. Healthcare measurements aimed at offering dental care to the entire population. This study evaluate the status of edentulous ridge and its association with, age, gender, dietary and nutritional factors education, and quality of life.

Material and methods: A cross sectional survey was conducted on 299 subjects among the rural population of Mangalore Taluk. The study involved completion of a predesigned proforma. Statistical analysis of the data was done using the SPSS version 17.0. Chi square test was used for data analysis and the level of significance was $p$ value $<0.05$

Results: In the study, the sample was composed of 165 males and 135 females, with 152 of them being vegetarians and 147 with mixed diet. Type 3 and type 4 ridge was found predominantly among the mixed diet and among those with Secondary level of education. Type 4 ridge was found predominantly in both the arches among those, who lived alone and predominantly among females in the mandibular edentulous arch.

Conclusion: The study shows that the type of ridge is affected by demographic factors, diet and quality of life. It proves conclusively that there exists a significant decrease in the quality of ridge in illiterates, which necessitates creating awareness on the importance of the nutrition and the effect on oral health.
\end{abstract}

Copy Right, IJAR, 2019,. All rights reserved.

\section{Introduction:-}

Food plays an important role for the survival of people across all age groups. It's adequate intake is necessary because of the nutrition required for the appropriate physiological functioning of the body which is accomplished by proper mastication, a complex neuromuscular activity ${ }^{(1,2)}$. It is also believed to play a role in people's social, emotional and psychological needs ${ }^{(1)}$. Nutritional deficiency, especially of proteins is very common among the older population ${ }^{(3)}$. Their diet many a time are challenging not only to dentists but also to their caretaker ${ }^{(2)}$.

Geriatric dentistry deals with dental care to the aged such as diagnosis, prevention and treatment associated with aging and age related disease. A great majority of aged people are either partially or completely edentulous. Ill fitting dentures may limit the intake of essential nutrients and consumption of favorite food ${ }^{(2)}$. 
The aged grouped form with all their teeth extracted is a problem tends to worsen when no healthcare measures are taken. Healthcare measurements aimed at offering dental care to the entire population. Knowledge on the influence of edentulism over the quality of life and diet of elderly individuals is important.

Additionally, low income and the lack of knowledge on how to spend the money available for food to the best advantage has lead to deprived nutrition ${ }^{(1)}$ thus suggesting a direct relationship between socio economic status and overall health and oral health.

The relationship between gender, dental disease, and tooth loss is inherently very complex and have been proven by studies that biology and social factors with being females are important risk factors for tooth loss and women most certainly have higher rates of tooth loss and edentulism. ${ }^{(4)}$

The purpose of this study is to evaluate the status of edentulous ridge and its association with, age, gender, dietary and nutritional factors education, and quality of life.

\section{Methodology:-}

A cross sectional survey was conducted among the rural population of Mangalore Taluk. The inclusion criteria were being subjects of 35 years or more in age with edentulous ridge. A total of 299 subjects who met the requirements of the inclusion criteria were informed of the nature of the investigation and their consent were obtained. Subjects who were not co-operative and who did not give consent were excluded from the study. All recording forms were numbered, but not named. Approval for the study was obtained from the institutional review board. The study involved completion of a predesigned proforma. It was structured in 2 parts which recorded the 1.Demographic profile (age, gender, education) 2.The type of ridge are grouped under type I-high well rounded ridge, type II is medium well rounded ridge, type III knife edge ridge, type IV- depressed ridge. The types of diet are vegetarian and mixed diet. Statistical analysis of the data was done using the SPSS version 17.0. Chi square test was used for data analysis and the level of significance was $p$ value $<0.05$

\section{Results:-}

A total of 299 subjects were involved in the study, the sample was composed of 165 males and 135 females, with 152 of them being vegetarians and 147 with mixed diet.

Table 1 presents the effect of age on the type of maxillary and mandibular edentulous arches .It was found that type 4 ridge was found predominantly among those aged more than 65 years of age in both the arches and type 1 ridge was found predominantly among the 35-44 years of age in both the arches.

Table 2 presents the effect of gender difference on the type of maxillary and mandibular edentulous arches. Type 2 ridge was found predominantly among males in the maxillary and mandibular edentulous arch and Type 4 ridge was found predominantly among females in the mandibular edentulous arch.

Table 3 presents the effect of education on the type of maxillary and mandibular edentulous arches. In the maxillary arch, Type 1 and type 2 ridges were found predominantly among those with PU level of education. Type 3 and type 4 ridges were found predominantly among those with Secondary level of education. In the mandibular arch, Type 1 was found predominantly among post graduates. Type 2 and type 3 ridges were found predominantly among those with PU level of education. Type 4 ridges were found predominantly among those with Primary level of education. Table 4 presents the effect of diet on the type of maxillary and mandibular edentulous arches. It was found that type 3 ridge and type 4 ridge was found predominantly among those with the mixed diet in both the arches and type 1 ridge was found predominantly among those with vegetarian diet in both the arches.

Table 5 presents the effect of quality of life on the type of maxillary and mandibular edentulous arches., Type 4 ridge was found predominantly in both the arches among those, who lived alone.

Table 1:-The effect of age on the type of maxillary and mandibular edentulous arches

\begin{tabular}{|l|l|l|l|l|l|l|l|}
\hline & & $35-44$ & $45-54$ & $55-64$ & $>65$ & total & P-value \\
\hline \multirow{2}{*}{ Maxillary ridge } & TYPE 1 & $40 \%$ & $34 \%$ & $25 \%$ & $1 \%$ & 88 & $<0.001$ \\
\cline { 2 - 8 } & TYPE 2 & $31 \%$ & $33 \%$ & $33 \%$ & $4 \%$ & 107 & \\
\hline
\end{tabular}




\begin{tabular}{|l|l|l|l|l|l|l|l|}
\hline & TYPE 3 & $2 \%$ & $23 \%$ & $32 \%$ & $44 \%$ & 57 & 47 \\
\cline { 2 - 8 } & TYPE 4 & $0 \%$ & $2 \%$ & $26 \%$ & $72 \%$ & 47 \\
\hline \multirow{5}{*}{ Mandibular ridge } & TYPE 1 & $54 \%$ & $40 \%$ & $6 \%$ & $0 \%$ & $54 \%$ & $<0.001$ \\
\cline { 2 - 8 } & TYPE 2 & $32 \%$ & $44 \%$ & $22 \%$ & $1 \%$ & $32 \%$ & $0 \%$ \\
\cline { 2 - 8 } & TYPE 3 & $0 \%$ & $11 \%$ & $54 \%$ & $35 \%$ & $0 \%$ \\
\cline { 2 - 8 } & TYPE 4 & $0 \%$ & $6 \%$ & $38 \%$ & $56 \%$ & $0 \%$ \\
\hline
\end{tabular}

Table 2:-The effect of gender difference on the type of maxillary and mandibular edentulous arches

\begin{tabular}{|l|l|l|l|l|}
\hline & & MALES & FEMALES & p-value \\
\hline \multirow{5}{*}{ Maxillary arch } & TYPE 1 & $59 \%$ & $41 \%$ & $<0.001$ \\
\cline { 2 - 4 } & TYPE 2 & $66 \%$ & $34 \%$ & \\
\cline { 2 - 5 } & TYPE 3 & $58 \%$ & $42 \%$ & 0.023 \\
\cline { 2 - 5 } Mandibular arch & TYPE 4 & $19 \%$ & $81 \%$ & \\
& TYPE 1 & $60 \%$ & $34 \%$ & \\
\cline { 2 - 5 } & TYPE 2 & $66 \%$ & $57 \%$ & \\
\cline { 2 - 5 } & TYPE 3 & $43 \%$ & $50 \%$ & \\
\cline { 2 - 5 } & TYPE 4 & $50 \%$ & & \\
\hline
\end{tabular}

Table 3:-The effect of education on the type of maxillary and mandibular edentulous arches

\begin{tabular}{|c|c|c|c|c|c|c|c|c|}
\hline \multirow{5}{*}{$\begin{array}{l}\text { Maxillary } \\
\text { ridge }\end{array}$} & & $\begin{array}{l}\text { ILLETRA } \\
\text { TE }\end{array}$ & $\begin{array}{l}\text { PRIMAR } \\
\mathrm{Y}\end{array}$ & $\begin{array}{l}\text { SECONDAR } \\
\mathrm{Y}\end{array}$ & PUC & $\begin{array}{l}\text { GRADUA } \\
\text { TE }\end{array}$ & $\begin{array}{l}\text { POST } \\
\text { GRADUATE }\end{array}$ & $\begin{array}{l}\mathrm{p}- \\
\text { value }\end{array}$ \\
\hline & TYPE 1 & $0 \%$ & $0 \%$ & $3 \%$ & $40 \%$ & $28 \%$ & $28 \%$ & \multirow{4}{*}{$\begin{array}{l}<0.00 \\
1\end{array}$} \\
\hline & TYPE 2 & $0 \%$ & $7 \%$ & $19 \%$ & $33 \%$ & $22 \%$ & $19 \%$ & \\
\hline & TYPE 3 & $26 \%$ & $28 \%$ & $16 \%$ & $11 \%$ & $11 \%$ & $9 \%$ & \\
\hline & TYPE 4 & $28 \%$ & $38 \%$ & $21 \%$ & $6 \%$ & $6 \%$ & $0 \%$ & \\
\hline \multirow{4}{*}{$\begin{array}{l}\text { Mandibul } \\
\text { ar ridge }\end{array}$} & TYPE 1 & $0 \%$ & $0 \%$ & $1 \%$ & $18 \%$ & $38 \%$ & $43 \%$ & \multirow{4}{*}{$\begin{array}{l}<0.00 \\
1\end{array}$} \\
\hline & TYPE 2 & $0 \%$ & $1 \%$ & $13 \%$ & $45 \%$ & $29 \%$ & $8 \%$ & \\
\hline & TYPE 3 & $17 \%$ & $14 \%$ & $22 \%$ & $24 \%$ & $7 \%$ & $8 \%$ & \\
\hline & TYPE 4 & $24 \%$ & $37 \%$ & $22 \%$ & $18 \%$ & $0 \%$ & $0 \%$ & \\
\hline
\end{tabular}

Table 4:-The effect of diet on the type of maxillary and mandibular edentulous arches

\begin{tabular}{|l|l|l|l|l|}
\hline & & Mixed & Vegetarian & p-value \\
\hline \multirow{5}{*}{ Maxillary ridge } & TYPE 1 & $34 \%$ & $66 \%$ & $<0.001$ \\
\cline { 2 - 4 } & TYPE 2 & $47 \%$ & $53 \%$ & \\
\cline { 2 - 4 } & TYPE 3 & $75 \%$ & $25 \%$ & \multirow{2}{*}{0.046} \\
\cline { 2 - 4 } & TYPE 4 & $50 \%$ & $48 \%$ & \\
\cline { 2 - 5 } Mandibular ridge & TYPE 1 & $37 \%$ & $63 \%$ & $57 \%$ \\
\cline { 2 - 4 } & TYPE 2 & $43 \%$ & $40 \%$ & \\
\cline { 2 - 5 } & TYPE 3 & $60 \%$ & $40 \%$ & \\
\cline { 2 - 5 } & TYPE 4 & $60 \%$ & & \\
\hline
\end{tabular}

Table 5:-The effect of quality of life on the type of maxillary and mandibular edentulous arches

\begin{tabular}{|c|c|c|c|c|c|c|c|}
\hline & & Wife & Daughter in law & Daughter & Son & Alone & p-value \\
\hline \multirow{4}{*}{$\begin{array}{l}\text { Maxillary } \\
\text { ridge }\end{array}$} & TYPE 1 & $23 \%$ & $22 \%$ & $27 \%$ & $17 \%$ & $11 \%$ & \multirow[t]{4}{*}{$<0.001$} \\
\hline & TYPE 2 & $27 \%$ & $21 \%$ & $30 \%$ & $16 \%$ & $6 \%$ & \\
\hline & TYPE 3 & $5 \%$ & $14 \%$ & $9 \%$ & $33 \%$ & $26 \%$ & \\
\hline & TYPE 4 & $2 \%$ & $26 \%$ & $9 \%$ & $17 \%$ & $47 \%$ & \\
\hline \multirow{4}{*}{$\begin{array}{l}\text { Mandibular } \\
\text { ridge }\end{array}$} & TYPE 1 & $23 \%$ & $22 \%$ & $33 \%$ & $17 \%$ & $5 \%$ & \multirow[t]{4}{*}{$<0.001$} \\
\hline & TYPE 2 & $30 \%$ & $22 \%$ & $34 \%$ & $14 \%$ & $30 \%$ & \\
\hline & TYPE 3 & $14 \%$ & $28 \%$ & $10 \%$ & $28 \%$ & $21 \%$ & \\
\hline & TYPE 4 & $1 \%$ & $21 \%$ & $7 \%$ & $21 \%$ & $50 \%$ & \\
\hline
\end{tabular}




\section{Discussion:-}

Dietary patterns are developed over an extended period of time and an individual's choice of diet are influenced by varying factors such as taste, aroma, texture, consistency, colour, shape, size, temperature, of food. Though the importance of eating fruits, vegetables, and dietary fiber is established, the extent to which dental status is associated with the intake of nutritious foods has not been studied extensively ${ }^{(5)}$. Teeth provide the ability to chew a wide variety of foods of different textures and nutritional values. Masticatory efficiency declines following tooth loss forcing humans to find an alternative in their dietary intake to compensate for the difficulty of eating certain foods ${ }^{(6)}$. The present study is cross sectional survey on status of edentulous ridge and its association with age, gender, education, diet and quality of life among adult rural population of mangalore taluk.

In the present study depressed ridges (type 4) were found in subjects greater than 65 years of age, this was in agreement with study by Pietrokovski et al. ${ }^{(7)}$ Who concluded that young elderly patients have slightly larger edentulous structures than old elderly patients. This may be because as age progresses higher osteoclastic activity more than the osteoblastic activity.

In the present study medium well rounded ridge (type 2) ridge was found predominantly among males in both the arches and depressed (type 4) ridge was found predominantly among females in the mandibular edentulous arch.This was in accordance with the study by Bando et al and Acharya et al ${ }^{(8,9)}$ who stated that the greater rate of alveolar bone loss within women is attributed to the accelerator effect of oestrogen deficiency on generalised mineral loss from the skeleton during and after menopause.

In the present study the depressed ridges (type 4) were found predominantly among those with Primary level of education. This may be as a result of lack of knowledge of balanced diet. Jung Ki Kim et al found that oral health problems were high amongst those with low level of education. He also mentioned higher prevalence of edentulism at younger ages among those with less education ${ }^{(10)}$.

On comparing the relationship of diet on the type of maxillary and mandibular edentulous arches. It was found that knife edge ridge (type 3) and depressed ridges (type 4) was found predominantly among those with mixed diet in both the arches and type 1 ridge was found predominantly among those with vegetarian diet in both the arches. This may be due to low consumption of non-vegetarian diet among edentulous patients due to difficulty in mastication which compromises nutrition thus resulting in poor ridge. The cooked Vegetarian meal being soft is easily consumed by edentulous subjects thus resulting in better nutrition. Brian et al concluded that the edentulism is associated with poor diet and compromised nutrition ${ }^{(7)}$. Literature searched revealed no research comparing diet and condition of the ridge.

In the present study the effect of quality of life on both the arches were analyzed and found that high well rounded ridge was found predominant among those who lived with their daughter and wife. Depressed ridge (type 4) was found predominantly among those, who lived alone. This may be due to good healthcare measurements were taken on time, lifestyle and have a balanced diet provided by the family which was not found among those who lived alone. This was in accordance with study conducted by Pierre Yves Cousson et al ${ }^{(11)}$ who concluded that participants living as couple are with good Geriatric Oral Health Assessment Index scores had better mini nutritional assessment.

\section{Conclusion:-}

The study shows that the type of ridge is affected by demographic factors, diet and quality of life. It proves conclusively that there exists a significant decrease in the quality of ridge in illiterates, which necessitates creating awareness, on the importance of the nutrition and the effect on oral health. Special care should be provided by the government officials to the individuals who are living alone. As a dentist, we should provide the elderly with a good set of denture and elicit its importance and use. It is important that periodic recall should be considered for elderly people to check for oral and nutritional health. It is also necessary to conduct programmes in rural population to increase awareness among the elderly regarding the importance of diet, and their effects on oral health. 


\section{References:-}

1. Ettinger RL. Changing dietary patterns with changing dentition: how do people cope?. Special Care in Dentistry. $1998 ; 18(1): 33-9$.

2. Toufiq HI, Al-Mendilawi LR, Arkan NT. Food consumption by complete denture wearers. Journal of baghdad college of dentistry. 2006;18(1):30-2.

3. Abbad, Nikhil. Nutrition Consideration and Oral Health Care for Edentulous Patients. International Journal of Preventive and Clinical Dental Research. 2017;4. 59-63. 10.5005/jp-journals-10052-0082.

4. Russell SL, Gordon S, Lukacs JR, Kaste LM. Sex/gender differences in tooth loss and edentulism: historical perspectives, biological factors, and sociologic reasons. Dental Clinics. 2013 1;57(2):317-37.

5. Nowjack-Raymer RE, Sheiham A. Association of edentulism and diet and nutrition in US adults. Journal of Dental Research. 2003 ;82(2):123-6.

6. Joshipura KJ, WILLETT WC, DOUGLASS CW. The impact of edentulousness on food and nutrient intake. The Journal of the American Dental Association. 1996 1;127(4):459-67.

7. Pietrokovski J, Harfin J, Levy F. The influence of age and denture wear on the size of edentulous structures. Gerodontology. $2003 ; 20(2): 100-5$.

8. Acharya S, Lohe VK, Bhowate RR. Evaluation and comparison of alveolar bone loss of maxilla and mandible in completely edentulous patients on digital panoramic radiographs. J Oral Med, Oral Sur, Oral Path \& Oral Radio. 2016;2:112-9.

9. Bando, K., Nitta, H., Matsubara, M., \& Ishikawa, I. (1998). Bone Mineral Density in Periodontally Healthy and Edentulous Postmenopausal Women. Annals of Periodontology, 3(1), 322-326

10. Kim JK, Baker LA, Seirawan H, Crimmins EM. Prevalence of oral health problems in US adults, NHANES 1999-2004: exploring differences by age, education, and race/ethnicity. Special care in dentistry. 2012 ;32(6):234-41.

11. Cousson PY, Bessadet M, Nicolas E, Veyrune JL, Lesourd B, Lassauzay C. Nutritional status, dietary intake and oral quality of life in elderly complete denture wearers. Gerodontology. $2012 ; 29(2)$ :e685-92. 